$\mathrm{DOE} / \mathrm{PC} / 88924--8$

DE9 1000854

$\mathrm{DOE} / \mathrm{PC} / 88924-08$

\title{
Thermodynamics of the Solvent Swelling of Coal
}

\section{Technical Progress Report \#8}

Thomas K. Green

\author{
Center for Coal Science \\ Department of Chemistry \\ Western Kentucky University \\ Bowling Green, KY 42101
}

For the Period June 1, 1990 to August 31, 1990

This report was prepared with the support of the U.S. Department of Energy, Grant No. DE-FG22-88PC88924. However, any opinions, findings, conclusions, or recommendations expressed herein are those of the author and do not necessarily reflect the views of DOE.

US/DOE Patent Clearance is not required prior to the publication of this document. 


\section{TABLE OF CONTENTS}

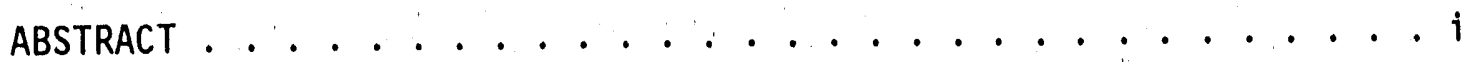

INTRODUCTION . . . . . . . . . . . . . . . . . . . . 1

EXPERIMENTAL . . . . . . . . . . . . . . . . . 2

Sample Preparation . . . . . . . . . . . . . . 2

Sorption Experiments . . . . . . . . . . . . . . . 2

RESULTS AND DISCUSSION . . . . . . . . . . . . . 6

FUTURE WORK . . . . . . . . . . . . . . . . . . . . . 11

REFERENCES . . . . . . . . . . . . . . . . . . . . 12

APPENDIX

"Rate of Benzene Sorption by 0-Alkylated Illinois \#6 Coals"

\section{DISCLAIMER}

This report was prepared as an account of work sponsored by an agency of the United Siates Government. Neither the United Sta: Government nor any agency thereof, nor any of their employees, makes any warranty, express or implied, or assumes any legal liability or responsibility for the accuracy, completeness, or usefulness of any information, apparatus, product, or process disclosed, or represents that its use would not infringe privately owned rights. Reference herein to any specific commercial product, process, or service by trade name, trademark, manufacturer, or otherwise does not necessarily constitute or imply its endorsement, recommendation, or favoritig by the United States Government or an;" agency thereof. The views and opinions of authors expressed herein do not necessarily state or reflect those of the United States Government or any agency thereof. 
Sorption of pyridine by the pyridine-extracts of three premium Argonne coals was studied at several relative vapor pressures at $50^{\circ} \mathrm{C}$ and $70^{\circ} \mathrm{C}$. The amount of pyridine sorbed by each extract increases linearly with pyridine vapor pressure. The extrapolated lines do not pass through the origin. At low pressures, a dual-mode sorption mechanism is proposed, whereby pyridine concurrently fills holes (microvoids) and dissolves into the extract. At higher pressures, we propose that the holes are saturated and that only dissolution is occurring. Dissolution thus increases linearly with pressure of pyridine. Heat of dilution were calculated from the slopes of the straight-line portions of the curves. All values are negative, becoming more negative in the order Wyodak, Illinois \#6, and Pittsburgh \#8.

In a related experiment, the pyridine sorption isotherms of the pyridineextract, pyridine-insoluble residue, and the whole coal were determined at $50^{\circ} \mathrm{C}$. For all materials, the amount of pyridine sorbed increases linearly with pressure of pyridine, with similar slopes. However, the intercepts are different for each material. The intercept for the pyridine-insoluble residue is three times that of the whole coal. It is well-established that pyridine-extraction increases the surface area of coals. The result is thus entirely consistent with our interpretation that the intercepts of these curves represent the amount of adsorbed pyridine.

Finally, the sorption of benzene vapors by 0 -alkylated Illinois \#6 coals were studied at $30^{\circ} \mathrm{C}$. The rate of benzene sorption increases dramatically upon 0 -methylation, indicating that coal-coal hydrogen bonds play a dominant role in controlling the rate of benzene sorption. This work was written in the form of a communication to be submitted for publication and is attached as an appendix. 


\section{INTRODUCTION}

The principal goal of this research is to develop an understanding of the thermodynamics of the swelling of coals in various solvents. The approach is unique in the sense that the uncrosslinked portion of the coal is being swollen, as opposed to the crosslinked portion. This approach avoids complications due to the crosslinked nature of coals, and allows the experimental data to be interpreted in terms of modern theories developed for polymer solutions.

We are currently working with the pyridine-extracts of three Argonne premium coals. The extract of each coal was exposed to pyridine at several relative pressures and $50^{\circ} \mathrm{C}$ and $70^{\circ} \mathrm{C}$ and the equilibrium weight of pyridine was measured. The amount of pyridine sorbed increases linearly with pressure for each extract. The extrapolated line yields a nonzero, positive intercept in each case. We interpret this intercept as the total amount of pyridine that fills holes or microvoids in the extract. If this interpretation is correct, it indicates that swelling (or dissolution) of the extract increases linearly with pyridine pressure (obeys Henry's law).

The solubility constants of the extract/pyridine systems were calculated from the slopes of the curves. The results show that pyridine solubility increases with rank of coal in the order Wyodak > I11inois \#6 > Pittsburgh \#8 extract. Heats of dilution were calculated from the solubility constanis. All values are negative, which is expected since pyridine is known to interact specifically with the polar hydroxyl groups in the extracts through hydrogen bonding. 


\section{EXPERIMENTAL}

\section{Sample preparation}

Argonne Premium coals were obtained from Argonne National Laboratory in ampoules of five grams of -100 mesh coal. The coal was first dried under vacuum at $105^{\circ} \mathrm{C}$ to constant weight and then analyzed for carbon, hydrogen, and nitrogen. Analys is found: Illinois \#6: C, 65.57; H, 4.66; N, 1.24: Pittsburgh \#8; C, 74.16; $H, 5.11 ; \mathrm{N}, 1.36 ;:$ Wyodak; $\mathrm{C}, 67.46 ; \mathrm{H}, 4.99 ; \mathrm{N}, 0.84$.

Approximately $4.5 \mathrm{~g}$ of the sample was Soxhlet-extracted with dry pyridine under argon for several days until the siphon liquid was clear. The pyridine solution was then filtered through a $0.4 \mu \mathrm{m}$ nylon membrane filter to insure removal of particulates and colloidal material. The filter did not plug. Most of the pyridine was reloved by rotovaporization under reduced pressure at 70 $80^{\circ} \mathrm{C}$. Approximately $200 \mathrm{~mL}$ of a methanol/water $(80 / 20$ vol.) mixture and $2 \mathrm{~mL}$ of conc. $\mathrm{HCl}$ were added to the flask and the mixture was stirred under nitrogen for two days. The solid extract was then filtered and dried under vacuum at $105^{\circ} \mathrm{C}$ for 24 hours. The extractability was $27.2 \%$ (wt.) for Illinois \#6, $29.8 \%$ for Pittsburgh $\# 8$, and $5: 2 \%$ for Wyodak.

\section{Sorption Experiments}

Sorption experiments using pyridine as solvent were carried out using a quartz spring balance shown in Figure 1. The balance consists of a quartz spring, a large 5 liter flask, vacuum inlet system, and MKS pressure transducer $(0-1000$ torr, $0.5 \%$ accuracy). The entire balance chamber, including transducer, is housed in a Precision Scientific circulating (forced air) drying oven, which is maintained at a constant temperature by a $I^{2} R$ thermowatch temperature regulator which activates a light bulb. 


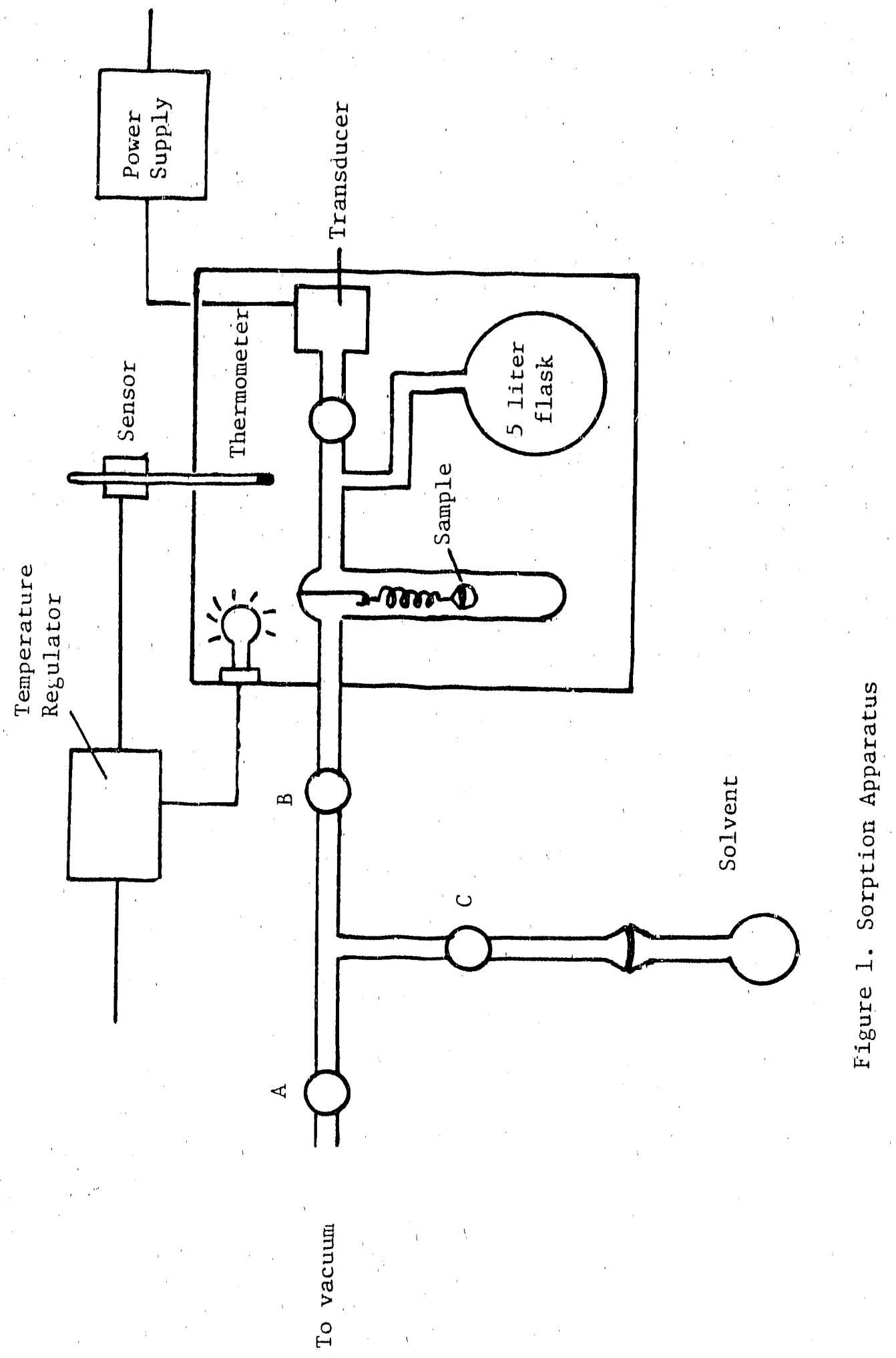


The sample is suspended from the quartz spring and, as the sample sorbs solvent, the spring extends until equilibrium is reached. The extension of the spring is measured through a window on the door of the oven using a sensitive Eberbach cathetometer (travelling telescope). The spring is calibrated at the appropriate temperature using standard weights before the experiment is conducted. The experiment, thus, allows determination of the mass of solvent sorbed by the sample at a given partial pressure and temperature. The purpose of the 5 liter flask to minimize pressure changes caused by sorption of solvent by the sample. Quartz springs of the type used here have a linear-extension versus suspended... weight relationship and exhibit no hysteresis with in the range of weights for which the spring is designed.

For the particular spring used in these experiments, the calibration factor was determined to be $0.48 \mathrm{~mm} / \mathrm{mg}$. The uncertainty of the cathetometer is \pm 0.1 $\mathrm{nm}$. Since two measurements must be made to obtain the weight of solvent, the uncertainty in the solvent weight is $0.2 \mathrm{~mm} \times 1 \mathrm{mg} / 0.48 \mathrm{~mm}= \pm 0.4 \mathrm{mg}$. In a typical experiment, $50 \mathrm{mg}$ of extract was used, so the uncertainty per gram of extract is $\pm 0.4 \mathrm{mg} / 0.050 \mathrm{~g}= \pm 8 \mathrm{mg} / \mathrm{g}$ extract.

The experimental procedure was as follows. Approximately $50 \mathrm{mg}$ of extract was placed in the quartz bucket and weighed on an electronic balance. The bucket and sample were then suspended on the spring. The hangdown tube was replaced and the system was evacuated to less than 0.1 torr and brought to the appropriate temperature $\left(50 \pm 0.02^{\circ} \mathrm{C}\right)$. The system was allowed to evacuate overnight. Purified pyridine was placed in the round bottom flask shown in Figure 1 and frozen with dry ice/isopropanol. Stopcock B was closed, and stopcock C was opened to evacuate air form the flask. Then stopcock $C$ was closed, and the pyridine was thawed and refrozen. Stopcock $C$ was again reopened for evacuation. This procedure insures removal of last traces of air. Stopcock $A$ was closed and 
stopcocks $B$ and $C$ were then opened unt 11 the appropriate pressure of pyridine was reached. After equilibrium was achieved, the pressure of pyridine was again raised. This procedure was repeated unt il the entire pressure range was covered. 


\section{RESULTS AND DISCUSSION}

The pyridine-extracts of the Argonne coals were exposed to pyridine at various vapor pressures at $50^{\circ} \mathrm{C}$. Several incremental sorption experiments were conducted in that, once equilibrium was attained at a particular pressure, the pressure was raised and the system was again allowed to attain equilibrium. The equilibrium amounts of pyridine sorbed by the extracts at $50^{\circ} \mathrm{C}$ are plotted against relative pressure of pyridine in Figure 2 . Note that there is a good straight-line correlation between sorption values and pressure for each extract. The curves drawn are least-squares fics.

The results in Figure 2 demonstrate that sorption of pyridine by the extracts obeys Henry's Law, i.e., the solubility of pyridine in the extract increases linearly with pressure. However, the curves do not pass through the origin. This result is similar to those of Michaels et al, who observed that the solubilities of several gases in polyethylene terephthalate obeyed Henry's Law. For two of the gases, carbon dioxide and ethane, the sorption isotherms were curved at low pressures but linear at higher pressures. They interpreted their results by proposing that sorption took $\mathrm{place}$ by two concurrent mechanisms at the lower pressures; ordinary dissolution and "hole-filling." At higher pressure, the holes or microvoids were saturated with only dissolution occurring. The intercept was interpreted as the total amount of sorption due to filling of the microvoids. Thus, a quantitative separation of the two processes was possible.

Following the work of Michaels et al., we suggest that the intercepts observed in Figure 2 represent the total amount of pyridine that fills holes in the extracts. If this interpretation is correct, it indicates that the holes are saturated at a relative pressure of 0.2 and that only dissolution of pyridine in the extract is occurring at this pressure and higher. 


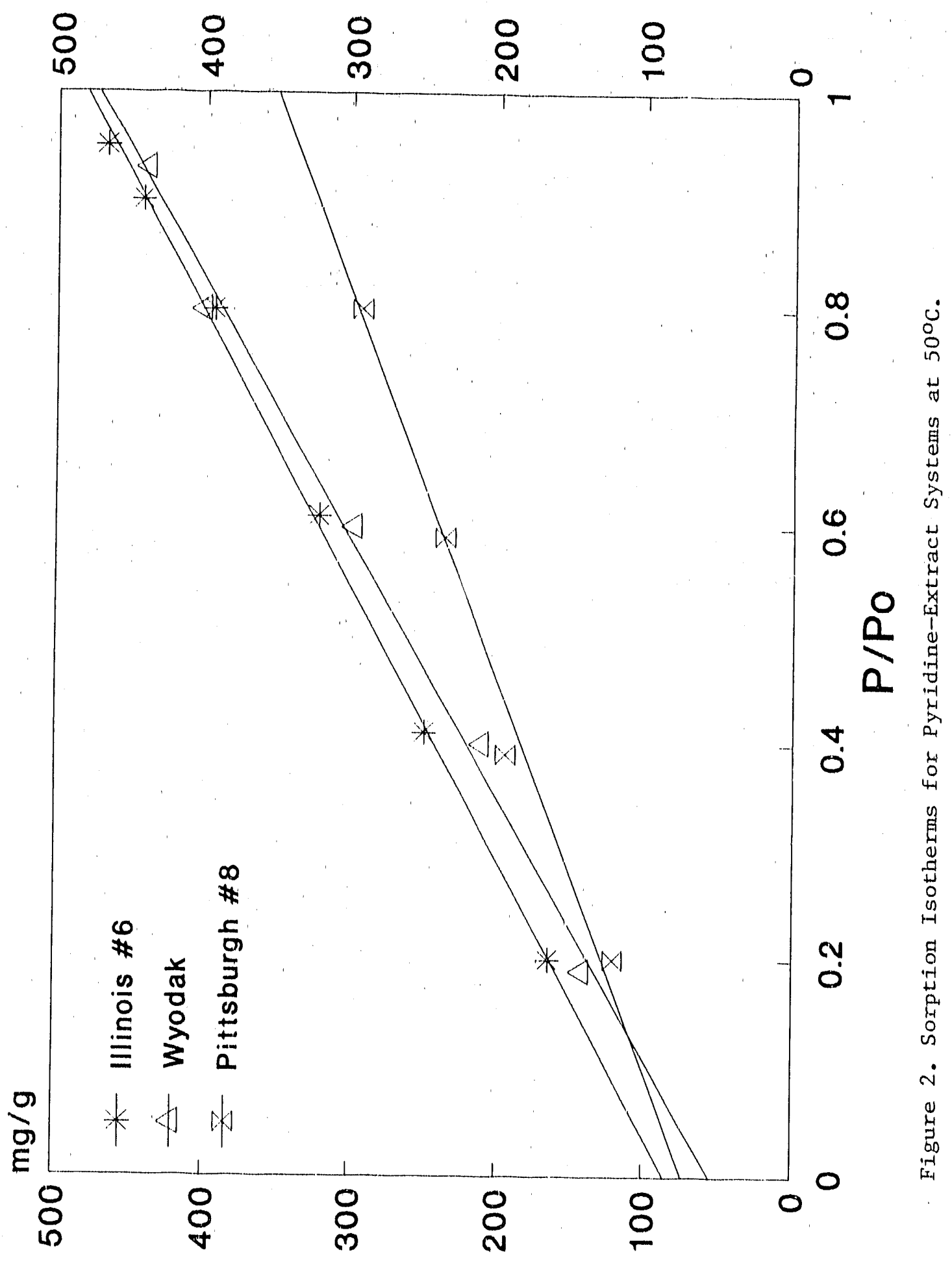


Solubility constants can be calculated from the data shown in Figure 2. The solubility constant, $K_{D}$ is simply the slope of the straight-line portion of the curve. The solubility constants are given in Tabie I. The constants show that the solubility of pyridine in the extract increases in the order Pittsburgh \#8<I11inois \#6 $<$ Wyodak.

\section{TABLE I}

Solubility Constants and Heats of Dilution for Extract-Pyridine Systems

\begin{tabular}{lcccc} 
Extract & $50^{\circ} \mathrm{K}, \mathrm{mg} / \mathrm{g}\left(\mathrm{p} / \mathrm{p}_{8}\right)^{\circ}$ & $\Delta \mathrm{H}_{\mathrm{dil}}, \mathrm{kcal} / \mathrm{mo1}$ \\
\hline Pittsburgh \#8 & $276(286)$ & $228(218)$ & -2.6 \\
I11inois \#6 & $395(396)$ & $331(332)$ & -2.0 \\
Wyodak & 419 & 386 & -1.0
\end{tabular}

${ }^{a}$ Number in parentheses represents duplicate experiment.

Heats of dilution were calculated from the sorption data using the following equation.

$$
\Delta H_{d i l}=\frac{-R T^{2} \ln \left(K_{01} / K_{02}\right)}{d T}
$$

where $K_{D 1}$ and $K_{D 2}$ are the solubility constants at $50^{\circ} \mathrm{C}$ and $70^{\circ} \mathrm{C}$, respectively. The results are summarized in Table I. Note that all values are negative, indicating a net exothermic interaction between the extracts and pyridine. Note also that there appears to be a rank dependence for $\Delta H_{d i l}$, with the lower rank coal (greater oxygen content) yielding the least negative value.

Given the straight-1ine nature of the isotherms shown in Figure 2, we belleved it worthwhile to investigate the sorption behavior of the corresponding 
whole coal and pyridine-insoluble residue. The results are shown in Figure 3 for the pyridine-extract, insoluble residue, and whole Illinois \#6 coal. All sorption values were corrected to a dry, mineral-matter fres basts. Note that the slopes of the lines for all materials are nearly the same, indicating that pyridine dissolves in each to approximately the same extent under the experimental conditions. The intercepts, however, differ significantiy, particularly for the residue and whole coal. According to our interpretation, the intercept represents that amount of pyridine adsorbed onto the surface. The result therefore suggests a large increase in surface area upon pyridineextraction. Petersen and Harris have noted that pyridine-extraction at $250^{\circ} \mathrm{C}$ for 4 hrs increased the surface area of a subbituminous coal by a factor of 2.5.2 The increase in surface area is attributed to new micropores that are formed during extraction. Our results are entirely consistent with their findings. 


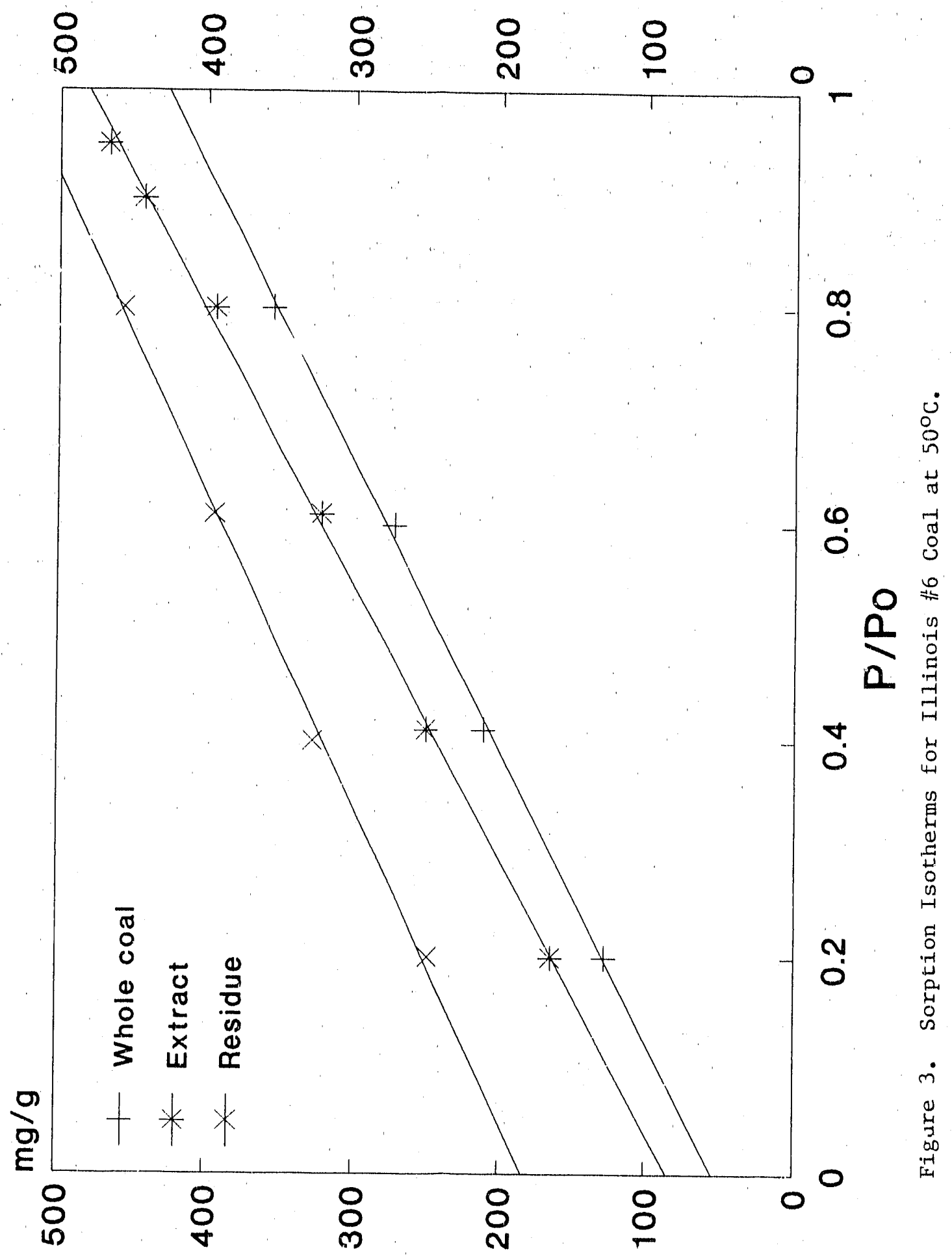




\section{FURTHER WORK}

The results presented to date using pyridine as solvent indicate that swelling and adsorption processes can be conveniently separated. Thus heats of dilution can be reliably determined for the various coal extract-pyridine systems. We plan to extend the study to $90^{\circ} \mathrm{C}$ for the extracts of three Argonne premium coals. We then plan to use tetrahydrofuran (THF) as a sorption solvent. THF is an excellent solvent for coals, yet does not hydrogen bond to hydroxyl groups as strongly as pyridine. We expect the heats of dilution to be, less exothermic. We hope to assemble a new quartz spring balance in order to enhance data collection. 


\section{REFERENCES}

1. Michaels, A. S.; Vieth, W. V.; Barrie, J. A., J. Appl. Phys., 1963, 34, 112.

2. Harris, E. C.; Petersen, E. E. Fuel 1979, 58, 599-60?. 
APPENDIX 


\section{Abstract}

The rate of benzene sorption of several 0-alkylated Illinois No. 6 coals was studied at $30^{\circ} \mathrm{C}$ and a relative pressure of 0.59 . The whole, untreated coal required nearly 100 hours to attain equilibrium. A coal from a blank experiment (no alkylating agent) attained equilibrium in 25 hours. In contrast, the 0 methylated coal attained equilibrium in one hour. The rate enhancement is attributed to the disruption of coal-coal hydrogen bond crosslinks by 0 methylation. Disruption of these crosslinks is thought to increase the rate of diffusion of benzene through the coal by rendering the coal more flexible. 0 butylated coal attained equilibrium in 0.5 hours but no further rate enhancement was observed for the 0-octylated coal. Benzene-extracted coals exhibited more rapid sorption of benzene in comparison to the unextracted coals. However, the extracted, 0 -alkylated coals sorbed benzene much more rapidly than the extracted coal from a blank experiment consistent with the important role of coal-coal hydrogen bonds in the sorption process. 


\title{
RATE OF BENZENE SORPTION BY O-ALKYLATED
}

\section{ILLINOIS NO, 6 COAL}

\author{
Thomas K. Green*, James E. Ba11, and Kevin Conkright \\ Department of Chemistry \\ Center for Coal Science \\ Western Kentucky University \\ Bowling Green, KY 42101
}

Sir: The rate-limiting step of many coal reactions is thought to be the diffusion of reagents to the reactive site within the coal structure. ${ }^{1}$ Thus, the diffusion of solvents through coals has been studied extensively in recent years with the aim of better understanding the factors that control the rate of diffusion. ${ }^{2-7}$ We report here on a study which demonstrates that the rate of benzene sorption by an Illinols No, 6 coal is markedly enhanced by simple 0 methylation of the hydroxyl groups. O-butylation increases the sorption rate even further, but no further enhancement is achieved by 0-octylation. The results suggest that coal-coal hydrogen bonds have a significant impact on the rate of diffusion of nonpolar solvents into coals.

The coal examined was Illinois No. 6 (Argonne Premium Coal Sample \#3). The dry coal was alkylated at room temperature according to the procedure of Liotta. ${ }^{8}$ Carbon and hydrogen analyses of the alkylated products established that 6.0 hydroxyl groups per 100 carbon atoms were reacted in each alkylation. A blank experiment was also conducted in which the coal was subjected to the conditions of the reaction except no alkylating agent was added.

To study the rate of benzene sorption by the coals, approximately $50 \mathrm{mg}$ of each coal was placed on a sample pan within a vacuum chamber of a Cahn 1000 electrobalance. After evacuation to less than 0.1 torr overnight, the sample was 
exposed to 70 torr of purified benzene vapor at $30^{\circ} \mathrm{C}\left( \pm 0.02^{\circ} \mathrm{C}\right)$. The relative pressure of benzene at this temperature is 0.59 . The rate of benzene uptake, measured in mg benzene sorbed per $g$ of coal, was monitored until equilibrium was estab1ished.

The sorption curves are shown in Flgure 1. The sorption of benzene by the dry, untreated coal is very slow. Equilibrium was finally achieved in about 100 hrs (see Table I). The coil from the blank experiment sorbed benzene faster, requiring about 25 hours to reach equilibrium. This result demonstrates that exposure of the coal to the tetrahydrofuran/water mixture used in the alkylation reaction alters the coal structure to some extent. As shown in Table $I$, this coal sorbed considerably more benzene than the untreated coal.

O-methylation of the coal dramalically affects the rate of benzene sorption, with equilibrium achieved in about one hour. The 0-butylated coal reached equilibrium in about 30 minutes, but no further rate enhancement was observed by 0 -octylation of the coal.

The more rapid uptake of benzene by the 0 -methylated coal could have at least two causes. First, it has been shown that 0 -methylation of an Illinois No. 6 coal causes an increase in its microporosity. ${ }^{8}$ This increase is attributed to the disruption of the secondary structure of coal (i.e. the coal-coal hydrogen bonds). As a result, benzene may have greater access into the structure due to increased surface area. On the other hand, 0-butylated and 0-octylated coals have been shown to have reduced microporosities compared to the 0 -methylated coal. Since these coals sorb benzene faster than the 0-methylated coal, this argument is somewhat weakened.

A more logical interpretation of the results, we believe, is related to the conformational freedom of the 0 -methylated coal. It is well established that coal-coal hydrogen bonds serve as "crosslinks" between coal macromolecules. ${ }^{8,9}$ Disruption of these crosslinks by 0 -methylation has been previously demonstrated 
to increase the amount of swelling of the coal in nonpolar solvents. ${ }^{9}$. In the absunce of these crosslinks, the coal can expand more to contain the solvent. We argue here that 0 -mothylation also makes the coal structure more flexible, which allows the coal to rearrange more rapidly in response to the solvent. Thus, rate of diffusion of benzene through the coal is enhanced as a result of 0-methylation. The enhanced rate of benzene sorption observed for the 0 butylated and 0-octylated coals may be related to the inherent flexibility of the added alkyl groups themselves. That is, some regions of these coals may be somewhat fluid in nature, allowing benzene even more rapld penetration.

Desorption curves were also obtained for the coals, which are shown in Figure 2. A large fraction of benzene could not be desorbed from the blank coal. as shown in Table $I$. In contrast, the 0 -methylated coal retained much less benzene after desorption, and practically all the benzene could be desorbed from the 0 -butylated and 0 -octylated coals.

Desorption, like sorption, can be considered an activated process. The retention of benzene by the underivatized coal is consistent with a high activation energy for the desorption process. Again, this can be attributed to the stiffness of the coal structure imparted to it by the coal-coal hydrogen bonds. Benzene itself should be incapable of disrupting these hydrogen bonds. 0-alkylation of the coal loosens the structure enough to allow substantially more benzene to escape.

The coals studied above were not extracted. In order to assess the effect of the extractable material on the sorption process, all coals were exhaustively extracted with berizene prior to exposure to benzene. The results are summarized in Table II. Note that the blank coal required nearly six hours to attain equilibrium, whereas the 0 -alkylated coals required only fifteen minutes or less. A11 extracted coals attained equilibrium faster than their unextracted counterparts. This effect might be attributed to increased surface area created 
by extraction with benzene. We have no difect evidence for increased surface a) an, but Peterson et, al, have noted that the surface area of a Roland seam coal increases by almost a factor of two by extraction of benzene at $150^{\circ} \mathrm{C} \cdot 10$ Increased surface area should result in more rapid penetration of benzene. All extracted coals sorb more benzene than the corresponding unextracted coal. This result can also be explained by an increase in surface area caused by extraction (more adsorbed benzene). We ure currently measuring the $\mathrm{CO}_{2}$-surface areas of the coals in order to assess this aspect more fully.

The sorption results obtained on this single coal suggest that the network of hydrogen bonds in the coal may control the rate of diffusion of some solvents/reagents into it. If so, simple oumethylation of the coal may be a convenient way of increasing the reaction rate of many coal reactions, particularly if the reaction is thought to be diffusion-controlled. We are currently examining the sorption behavior of other coals and their alkylated derivatives to see if they might behave similarly.

Acknowledgement: The generous support of the U.S. Department of Energy, Grant No. DE-FG22-88PC88924, and the Research Corporation is acknowledged.

\section{References:}

1. Larsen, J.W.; Green, T.K.; Chonhury, P.; Kuemmerle, E.W. in Coal Structure, Gorbarty, M.L., Ouchi, K.; Eds.; Amertcan Chemical Soctety: Washington, D.C., 1981, Chapter 18.

2. Brenner, D. Nature (London) $1983, \underline{306}, 772-773$.

3. Brenner, D. Fue1 1983, 62, 1347-1350.

4. Hsleh, S.T.; Duda, J.I. Polym, Mater, Sc1, Eng, 1984, 51, 703-706.

5. Peppas, N.A.; Lucht, L.M. Chem. Eng. Commun, 1985, 37, 334-354. 
6. Barr-Howe11, B.D.; Peppas, N.A.; Winslow, D.N. Chem. Eng Zommun. 1986, 43. $301-315$.

7. Barr-Howe11, B.D.; Peppas, N.A.; Squires, T.G. J.App1. Polym, Sc1. 1986, 31; 39.53 .

8. Llotta, R., i Rose, K; Hippo, E. J, Org. Chem, 1981, 46, 277.

9. Larsen, J.W.; Green, T.K.; Kovac, J. J, Org. Chem, 1987, 50, 4729.

10. Medelros, D.; Peterson, E.E. Fuel 1979, 58, 531-533. Table I. Equilibrium Sorption Data for Benzene and 0-Alkylated
Illinols No. 6 Coal at $30^{\circ} \mathrm{O}\left(\mathrm{p} / \mathrm{p}_{0}=0.59\right)$

\begin{tabular}{|c|c|c|c|}
\hline Coal & $\begin{array}{c}\text { Time to } \\
\text { Equilibrium (hrs,) }\end{array}$ & $\begin{array}{l}\text { Equi11brium } \\
\text { Amount }(\mathrm{mg} / \mathrm{g})^{a}\end{array}$ & $\begin{array}{l}\text { Percentage } \\
\text { Desorbed }\end{array}$ \\
\hline Untreated & $\sim 100$ & 127 (121) & $\cdots$ \\
\hline Blank & $\sim 25$ & $183(175)$ & 80 \\
\hline O-Methylated & $\sim 1$ & 167 (162) & 97 \\
\hline 0-Butylated & -0.5 & 162 & $>99$ \\
\hline O-Octylated & $\sim 0.5$ & 148 & $>99$ \\
\hline
\end{tabular}

Table II, Equilibrium Sorption Data for Benzene and Benzene-Extracted IIIInois No, 6 Coals at $30^{\circ} \mathrm{C}\left(\mathrm{p} / \mathrm{p}_{0}=0,59\right)$

\begin{tabular}{|c|c|c|c|c|}
\hline Coal 1 & $\frac{\begin{array}{c}\text { Extractable } \\
(\text { dmmf })\end{array}}{}$ & $\begin{array}{c}\text { Time to } \\
\text { Equilibrium (min). }\end{array}$ & $\begin{array}{l}\text { Equilibrium } \\
\text { Amt } \quad(m g / g)^{a}\end{array}$ & $\begin{array}{r}\text { Percentage } \\
\text { Desarbed }\end{array}$ \\
\hline Untreated & 2 & $\cdots$ & $\cdots$ & $\cdots$ \\
\hline Blank & 6 & -300 & 217 & - \\
\hline 0-Methylated & 20 & $\sim 15$ & 226 & 88 \\
\hline 0-Butylated & 18 & -10 & 191 & 98 \\
\hline 0-Octylated & 23 & $\sim 10$ & 173 & 99 \\
\hline
\end{tabular}




\section{Figure Captions}

Figure 1. Sorption of Benzene by 0-Alkylated Illinols No, 6 Coals at $30^{\circ} \mathrm{C}$ and Relative Pressura of 0.59 .

Figure 2. Desorption of Benzene by 0-Alkylated Illinols No, 6 Coals at $30^{\circ} \mathrm{C}$ Undar Vacuum $(<0.1$ torr $)$. 

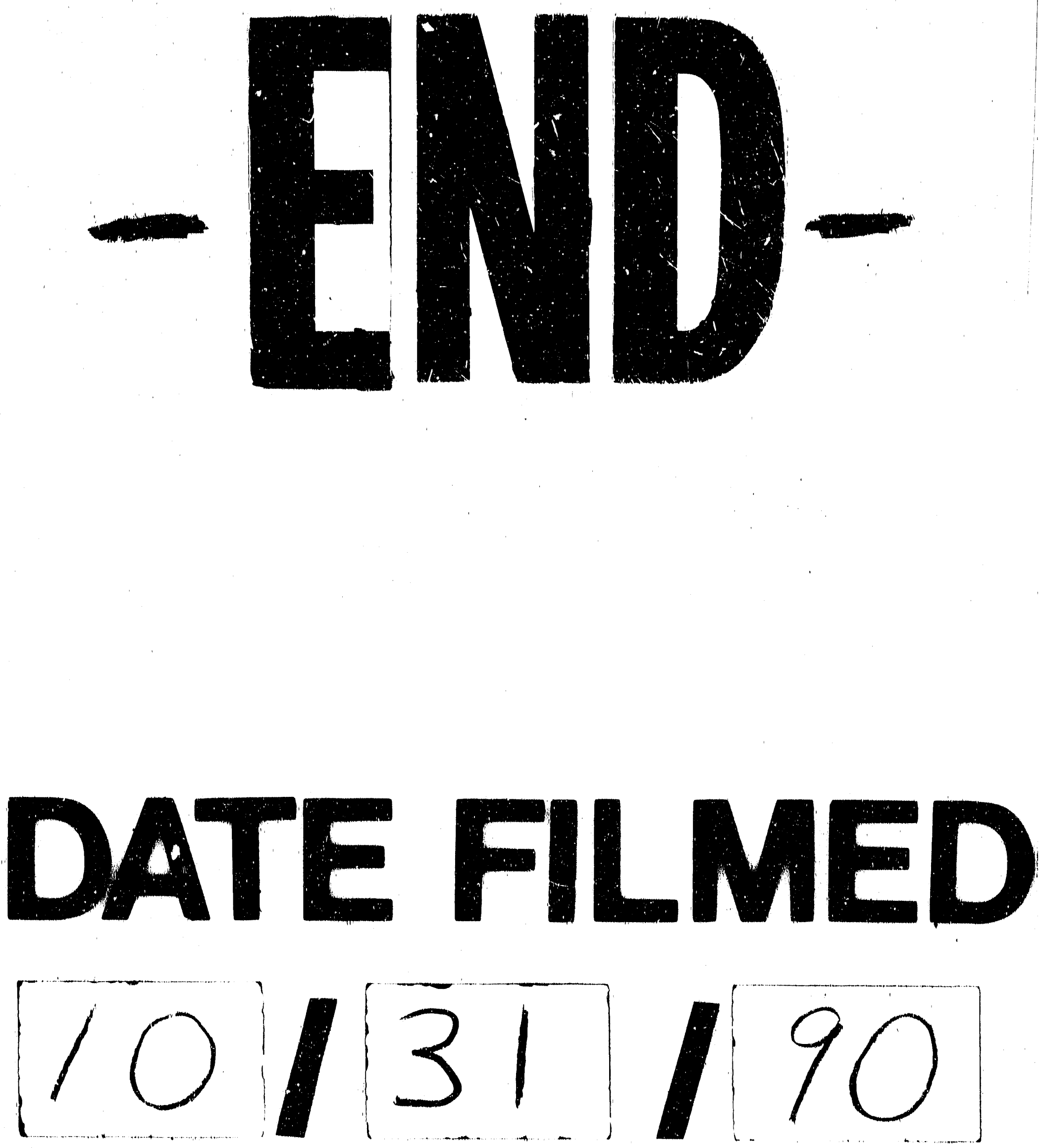


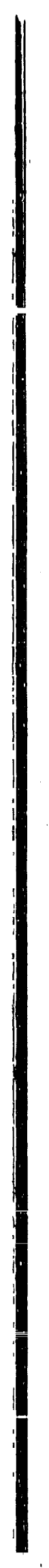

